\title{
O SISTEMA NACIONAL DE EDUCAÇÃO NARRADO NO DOCUMENTO BASE DAS CONFERÊNCIAS NACIONAIS DE EDUCAÇÃO/CONAE E A GESTÃO DA ESCOLA CONTEMPORÂNEA 1
}

http://dx.doi.org/10.5902/2176217110643

\author{
Ana Paula da Silva Pozzobon Castanho \\ Universidade Federal de Santa Maria, Brasil.
}

Resumo

Esta pesquisa analisa quais orientações, para a gestão democrática, inclusão e diversidade, nos oferece o documento base da Conferência Nacional de Educação/Conae na melhoria da gestão da escola pública contemporânea. Também busca analisar como estes princípios orientadores aparecem no projeto pedagógico da Escola Municipal de Lagoa Vermelha - RS. Apresenta-se, aqui, particularidades acerca da gestão educacional democrática brasileira na atualidade em uma escola contemporânea apoiando-se no referencial teórico para apontar as tendências apresentadas pela educação que estão em vigor no país, bem como, suas relações com os princípios orientadores da presente pesquisa. Para tanto, a metodologia utilizada baseia-se na abordagem qualitativa de caráter documental, desenvolvida a partir da busca de informações em documentos que não receberam qualquer tratamento científico.

Palavras-chave: gestão democrática, inclusão, diversidade, políticas públicas.

\section{THE NATIONAL EDUCATION SYSTEM NARRATED IN THE BASE DOCUMENT OF NATIONAL CONFERENCES ON EDUCATION / CONAE AND MANAGEMENT SCHOOL CONTEMPORARY BRAZILIAN}

\begin{abstract}
This research examines which guidelines for the management of democracy, inclusion and diversity, provides us with the base document of the National Conference on Education/Conae Conae improved management of contemporary public schools. It also seeks to analyze how these guiding principles appear in the educational project of the Municipal School of Lagoa Vermelha RS. It is presented here in particular about the democratic management of education in Brazil today in a contemporary school building on the theoretical point to the trends presented in education that are in force in the country, as well as its relations with the guiding principles of this research. For this purpose, the methodology is based on the qualitative approach of documentary character, developed from the information search in documents that have not received any scientific treatment.
\end{abstract}

Key-words: democratic management, inclusion, diversity, public politics.

\footnotetext{
${ }^{1}$ Este artigo é a síntese do trabalho monográfico apresentado no Curso de Especialização em Gestão Educacional do Centro de Educação da Universidade Federal de Santa Maria. Foi orientado pela professora Leandra Bôer Possa.

Regae: Rev. Gest. Aval. Educ.

Santa Maria

v. 2

ก. 3

Jan./jun. 2013

p. 17-26
} 


\section{Introdução}

uando ingressei no curso de Especialização em Gestão Educacional da UFSM, em 2009, recém formada no curso de Graduação em Educação Especial pela mesma instituição de ensino, pensava, muitas vezes, que o ensino era fomentado apenas pela legislação e pela trajetória de experiências de autores e professores do passado. Mas, conforme aprofundava e desenvolvia minhas leituras, percebia que novas perspectivas, ou melhor, que muitas maneiras de gestar a educação foram constituindo a história da educação no Brasil e no mundo. É a gestão que possibilita dar as linhas que hoje traçamos na educação de um país, verifiquei que a educação é, de fato, um processo em constante transformação, que requer a relação entre meios políticos, meios pedagógicos, meios institucionais, enfim, que é cercada por uma rede social, que visa à qualidade da educação para todos, conforme a legislação atual sustenta.

Neste trabalho faço uma breve retomada sobre o tema da educação inclusiva, tema recorrente na gestão educacional do país que toma como perspectiva a Educação para todos como política pública de Estado. Para dar conta deste trabalho, busco situar a minha experiência como professora e como participante das discussões de gestão educacional, dialogando sempre com o referencial apresentado em um dos principais documentos produzidos para a discussão da educação do país que foi o documento base das conferências nacionais de educação/Conae.

O documento base da Conae é um instrumento que serviu como base para a construção de diretrizes para o Plano Nacional de Educação. Foi construído em conferência nacional no ano de 2010, para aprovação das metas de 2011-2020, após as conferências municipais e estaduais realizadas em todo o país, para tanto é um documento elaborado de maneira democrática e de fundamental relevância para a construção da gestão democrática participativa da educação no Brasil.

Como educadora especial, trabalho em Sala de Recursos Multifuncional no município de Lagoa Vermelha, no Rio Grande do Sul, com alunos que apresentam dificuldades de aprendizagem e deficiência, e que se encontram incluídos em escolas regulares. Por meio de minha prática na área educacional, percebo que o processo de inclusão, constitui-se em estabelecer uma nova relação entre espaço e tempo de ensinar e aprender.

O professor tem o papel de promover à apropriação dos saberes, procedimentos e atitudes por parte dos alunos, mediando a aquisição dos conhecimentos educativos através desta nova relação entre o espaço e tempo de ensinar e aprender.

Em função disto a escolha por uma Escola Municipal do município de Lagoa Vermelha se dá pelo fato de ser a única escola municipal que tem a Sala de Recursos Multifuncional e é considerada, perante a política municipal de educação, como uma escola inclusiva, visto que a maioria dos alunos incluídos no município estuda neste ambiente escolar.

Na controvérsia entre realidade escolar e gestão pública da educação, é possível traduzir uma idéia corrente no país sobre a impossibilidade da escola em dar conta dos processos educativos de crianças tão diferentes e diversas. Neste discurso, a escola é narrada como o lugar que não está preparado para esperar um aluno especial, 
considerado pela legislação atual ${ }^{2}$ como aluno que possui necessidades educacionais especiais como: deficiência mental, auditiva, surdez, cegueira, altas habilidades e transtornos globais do desenvolvimento, registram-se aí a segregação e a dificuldade da inclusão.

Outra idéia percebida no ambiente educacional e familiar é a espera que as estruturas e recursos possam oferecer a possibilidade de cura das dificuldades dos alunos, esperando que todos cheguem num modelo de padronização, modelo em que todos aprendem da mesma maneira e no mesmo tempo, formando assim uma sala de aula de indivíduos iguais, sem distinções. Ou seja, a diversidade é considerada na porta de entrada da escola, mas espera-se que na porta de saída estejam todos os alunos iguais.

O que me leva a esta discussão neste trabalho é a percepção acerca do contexto da escola e da percepção de que alguns profissionais que trabalham nas escolas têm pouco envolvimento com as diretrizes de gestão da escola ou das discussões sobre a gestão educacional do país no âmbito das políticas públicas. Percebo ainda, que questões como a gestão democrática, a inclusão e a diversidade, apesar de fazerem parte de textos educacionais no âmbito das políticas de estado, podem não ser de domínio conceitual e prático no âmbito da escola e dos profissionais que atuam nela.

Nesse contexto, apresento as seguintes questões de análise: Quais orientações sobre gestão democrática, inclusão e diversidade nos oferece hoje o documento base da Conferência Nacional de Educação/Conae para a gestão da escola pública contemporânea? Como estes princípios orientadores aparecem no projeto pedagógico da escola municipal nos aspectos relacionados às relações com a comunidade escolar, diretrizes pedagógicas e plano de ação, entre outros, tomando como referência este documento?

Por estes motivos e diante dos pressupostos de valorização de todos os segmentos educacionais e sociais de uma sociedade democrática descritos no documento base do Conae, propus-me, nessa pesquisa, a desenvolver os seguintes objetivos:

a) analisar no documento base das Conferências Nacionais de Educação/Conae os princípios orientadores que nomeiam a gestão democrática, a inclusão e a diversidade;

b) perceber, pelo estudo do projeto político pedagógico de uma escola da rede municipal de ensino do município de Lagoa Vermelha-RS, como se apresentam estes princípios orientadores: gestão democrática, inclusão e diversidade.

Para atender as proposições elencadas nesta pesquisa, a metodologia utilizada baseia-se na abordagem qualitativa de caráter documental, que dela faz parte a obtenção de dados descritivos mediante contato direto e interativo do pesquisador com o objeto de estudo.

\section{Gestão da escola contemporânea brasileira e suas perspectivas atuais}

$\mathrm{Na}$ sociedade contemporânea, rapidamente ocorrem transformações tanto no mundo do trabalho, quanto nas formas de comunicação que fazem com que esses acontecimentos incidam de maneira retumbante, nas escolas. Essas mudanças e

\footnotetext{
2 Documentos referenciados como: Política Nacional de Educação Especial, Política Nacional de Educação Especial na perspectiva da educação inclusiva, Plano Decenal de Educação, LDB/96, entre outros documentos com caráter de decretos, portarias e pareceres do MEC.
} 
evoluções vêm aumentando significativamente os desafios em relação às práticas e paa a criação de uma nova perspectiva cultural como objetivo do sistema educacional brasileiro. É, portanto, desafiador oportunizar o desenvolvimento humano, cultural, científico e tecnológico da população, para que o povo possa ter as condições de enfrentar as novas exigências do mundo contemporâneo.

Essas idéias com relação à nova visão da educação e de sua qualidade interferem em mudanças de articulações nas políticas educacionais, tais como: descentralização do poder, efetivando a democratização da gestão escolar, maior autonomia das escolas, reorganização curricular, formas de gestão e direção das escolas feitas de maneira diferenciada e novas tarefas exigidas para os professores, tarefas nas quais podemos referenciar $\mathrm{o}$ trabalho com diferentes possibilidades de aprendizado dos alunos, 0 trabalho com o diferente e com 0 irregular, fato que causa muita estranheza aos professores, pois estão ainda muito vinculados ao conceito de igualdade, fato que hoje já não podemos mais confirmar na realidade da escola atual.

Para se entender a organização escolar atual, é preciso associá-la a alguns aspectos mais gerais da sociedade, como economia e política, focalizando as relações existentes entre eles e a escola.

A reforma educacional atual, que se inicia em 1990 no Brasil, tem o Plano Decenal de Educação como um de seus maiores marcos. Este documento foi destinado a cumprir, no período de dez anos (1993 a 2003), as resoluções da Conferência Mundial sobre Educação para Todos, realizada em Jomtien, Tailândia, em 1990. O Plano Decenal de Educação foi "concebido para ser instrumento-guia pela recuperação da educação básica do País e estabelecido com a participação de todas as esferas e agentes do processo educativo" (Brasil, 2009, p. 1).

Demonstrando-nos que as mudanças sugeridas pelo documento da Conae são mudanças baseadas nos pressupostos de uma educação que exigirá atenção específica, bem como maiores recursos atitudinais, educacionais, financeiros e pessoais disponíveis para dar respostas às suas necessidades de aprendizagem, significando que a escola deve realmente pertencer ao sistema nacional articulado para que seja garantido o direito para efetivação da educação para todos.

Pensar em educação, nesse sentido, significa pensar em novas atitudes frente ao aluno, à escola e às políticas vigentes em nosso país. O que implica que a escola precisa fazer parte de uma rede de políticas de assistência e educação que são bem mais amplas e complexas do que a própria instituição escolar.

Verificamos que os três princípios orientadores da nossa pesquisa: gestão democrática, inclusão e diversidade, devem andar juntos na trajetória escolar, pois deve haver uma nova postura dos educadores e gestores com relação à qualidade do ensino, a permanência dos alunos na escola e a efetivação das aprendizagens adquiridas pelos alunos no ambiente escolar. É necessário esse "caminhar juntos", visto que a educação não é mais uma enxurrada de informações destinadas ao aluno, mas sim uma troca entre professor e aluno, que faz com que o conhecimento tenha significado e seja relevante para o futuro dos estudantes.

Uma troca, não somente entre o professor e o aluno, mas também com relação às políticas públicas em educação, que visam à melhor qualidade de vida dos alunos, ampliação da educação obrigatória, garantia de padrões de qualidade de ensino, 
efetivação das diretrizes de ensino, implementação de um sistema de avaliação voltado ao subsídio do processo de gestão educativa, programas suplementares e de apoio pedagógico aos alunos, ambiente adequado, equipamentos em condições, biblioteca, laboratórios, programas de cultura de paz, contra trabalho infantil, violência, definição dos custos de um aluno que assegure condições de educação de qualidade, docentes disponíveis em todas as áreas, TICs, planejamento e gestão coletiva de trabalho pedagógico, entre muitas outras atitudes que efetivam a qualidade do ensino em toda sua extensão, desde a educação infantil até o ensino superior (Conae, 2009).

\section{Conae e as orientações sobre gestão democrática, inclusão e diversidade}

A leitura realizada a partir do documento referência da Conae - Construindo o Sistema Nacional Articulado de Educação: o Plano Nacional de Educação, suas diretrizes e estratégias de ação, trouxeram a compreensão de algumas das estratégias que a política nacional visa quando se reporta ao termo educação de qualidade, pois é possível perceber que esse documento tem como finalidade nortear as discussões acerca da educação no país, para que consigamos garantir a valorização de todos os segmentos educacionais e sociais em uma sociedade democrática, bem como a consolidação de um Sistema Nacional de Educação, que ainda não é totalmente definido no nosso país.

O documento base da Conferência Nacional de Educação é um instrumento que serviu como base para a construção de diretrizes para o Plano Nacional de Educação. Foi construído em conferência nacional no ano de 2010, para aprovação das metas de 2011 2020 , após as conferências municipais e estaduais realizadas em todo o país.

O novo plano nacional de educação dá relevo à elaboração de currículos básicos e avançados em todos os níveis de ensino e à diversificação de conteúdos curriculares, prevendo a correção de fluxo e o da defasagem idade-série. São estabelecidas metas claras para o aumento da taxa de alfabetização e da escolaridade média da população, fato que corrobora com a política nacional vigente em nosso país.

Dessa forma, coloca-se em voga alguns dos conceitos básicos que se referem ao texto, e ampliando a discussão a cerca da formação do sistema nacional integrado de educação brasileira que visa à qualidade do ensino para todas as esferas da população brasileira a qual fazemos parte e que nos mostra tantas desigualdades ainda é que verifico que o documento referência da Conae nos traz diferentes estratégias e metas de abordagem com relação à educação.

Voltando-me às três orientações que norteiam minha pesquisa que são gestão democrática, diversidade e inclusão, verificam-se quais os aspectos relevantes descritos no corpo do texto do documento referência do Conae e que nos demonstram a efetividade destas ações perante a educação de qualidade para todos e que fazem uma articulação com o projeto político pedagógico das escolas do país.

Percebemos que os princípios de gestão democrática, diversidade e inclusão, que permeiam a presente pesquisa, estão sempre em voga nos comentários de todos os eixos do documento base da Conae, e que está é uma busca significativa de qualidade em educação, pensar nos direitos, nas relações sociais, na participação democrática dentro do ambiente escolar.

E não somente isto, pensar também em maneiras de como conseguir integrar todas estas esferas, buscando a qualidade efetiva da educação, visando sanar o analfabetismo, 
a evasão escolar, a valorização do profissional em educação, que apesar de ainda não ser tão valorizado no nosso país, sabemos ser a base fundamental do inicio de todos estes processos que percorremos ao longo de nossa formação social como cidadãos ativos dentro do ambiente em que vivemos e convivemos.

O documento base da Conae traz novas perspectivas para a educação, porque foi feito em conjunto com a sociedade, fator que colabora para sua efetivação, pois, como sabemos nada acontece sem ação efetiva da sociedade e esta ação somente acontecerá com a educação, visto que as reformas e novas diretrizes visualizadas nas discussões realizadas em todas as conferências municipais, regionais e federais sobre educação estão buscando basear-se na realidade atual, visando às dificuldades percebidas, pelos professores, pais, empresas, enfim, por todos que participam do caminho da educação.

\section{Análise do projeto político pedagógico da escola}

O projeto político pedagógico da escola deve ser entendido como o instrumento e processo de organização da escola que tem como propósito a explicitação dos fundamentos teóricos e metodológicos da escola, os objetivos propostos para o trabalho dentro da instituição, o tipo de organização e as formas de implementação e de avaliação que transcorrem dentro do ambiente escolar.

Segundo Libâneo,

a educação escolar tem a tarefa de promover a apropriação de saberes, procedimentos, atitudes e valores por parte dos alunos, pela ação mediadora dos professores e pela organização e gestão da escola. A principal função social e pedagógica das escolas é a de assegurar o desenvolvimento das capacidades cognitivas, operativas, sociais e morais pelo seu empenho na dinamização do currículo, no desenvolvimento dos processos de pensar, na formação da cidadania participativa a na formação ética. (2001, p. 137)

Sendo assim, o projeto pedagógico de escola deve priorizar a formação do aluno como um todo, percebendo e contemplando todas as esferas de seu pleno desenvolvimento para que a função da escola seja efetivada.

Conforme a leitura do projeto político pedagógico da escola municipal que foi analisada na presente pesquisa, percebeu-se que a escola trabalha com princípios de diversidade e inclusão, na qual todos os alunos trabalham de maneira coletiva, mas com professores ainda despreparados, sem formação específica ou continuada sobre as questões referentes à inclusão.

Quase todos, enquanto comunidade escolar, buscam auxílio para o trabalho com os alunos inseridos no ambiente escolar, mas percebe-se que ainda não está totalmente formada a percepção sobre o contexto da escola por parte de alguns profissionais que tem pouco envolvimento com as diretrizes de gestão da escola ou das discussões sobre a gestão educacional do país no âmbito das políticas públicas é evidente.

Nota-se que a escola rege-se pela perspectiva da gestão democrática participativa, onde todos são agentes de transformação e todos têm sua parcela de competências e desafios a traçar, objetivando o que a Conae e o Plano Nacional de Educação nos trazem, uma realidade na qual a educação é para todos e por todos. 
Uma educação com qualidade e que respeite as diferenças e individualidades dos envolvidos no ambiente escolar, proporcionando a todos a efetivação da aquisição dos conhecimentos que os coloquem como cidadãos plenos de seus direitos e deveres para com a sociedade é o que esta escola almeja.

Para tanto, se faz necessário repensar as atitudes que vivenciamos ao longo deste estudo do projeto pedagógico da escola. É emergencial a necessidade de discussões, grupos de estudo, palestras, enfim, ações voltadas ao esclarecimento de tais questões, pois, para que a escola seja de fato um ambiente estimulador e rico em aprendizagens todos deve estar e sentir-se envolvidos.

\section{Considerações finais}

O presente estudo, que foi elaborado a partir da necessidade de compreensão dos princípios de gestão democrática, inclusão e diversidade que orientam a política nacional na construção democrática e participativa do sistema educacional, trouxe a possibilidade de verificar quais as atitudes que estão sendo realizadas no país com relação à educação de qualidade objetivada em diversas conferências nacionais e internacionais que vem acontecendo há alguns anos.

Pensar nas orientações sobre gestão democrática, inclusão e diversidade que nos oferece o documento base da Conferência Nacional de Educação/Conae para a gestão da escola pública contemporânea e, como estes princípios orientadores aparecem no projeto pedagógico da Escola Municipal foi tarefa importante, pois a contemporaneidade da escola exige isso.

Já não se pode admitir mais um processo de gestão da escola construído somente com a visão do diretor, administrador responsável pela escola. Faz-se necessária uma construção coletiva, que leva em conta a participação e a valorização dos interesses da comunidade escolar, englobando os elementos técnicos do projeto pedagógico com os anseios em relação à educação, formando a noção de diálogo dentro do ambiente escolar.

Percebe-se que o princípio de gestão democrática, mesmo que implícito, é verificado no projeto pedagógico da escola. Pode-se observar-se em seu contexto a relação da distinção de autonomia dada a todos os elementos constituintes do projeto, que tem poder de atuar em diferentes momentos nas decisões escolares e que tem capacidade de gerir o ambiente escolar dentro da comunidade a qual faz parte e está inserida.

Ainda não é perceptível a relação entre os princípios norteadores da presente pesquisa com o que está escrito em todas as esferas do planejamento escolar, mas a possibilidade de atuação frente à realidade escolar existe e este já pode ser considerado um fator de destaque, visto que traz a possibilidade de diálogo entre a comunidade escolar. Baseando-se nas perspectivas das metas e diretrizes do Plano Nacional de Educação que está em vias de ser confirmado pelo governo federal.

Com relação ao princípio da diversidade e inclusão, encontramos relações que tratam das políticas de acesso e permanência de todos na escola, também com relação ao trabalho de respeito às diferenças para com toda a comunidade escolar. Isso favorece a noção de diversidade na sociedade atual, na qual somos cidadãos diferentes, temos nossos valores e princípios. Sendo assim, a escola não deve rotular ou questionar estes valores distintos, dando assim, ênfase ao respeito e a dignidade do individuo. 
Discutir possibilidades de ação frente aos limites impostos tanto pela sociedade, quanto pelos instrumentos utilizados pela sociedade para embargar atitudes que respeitem as diferenças individuais. Respeitar os diferentes ritmos de aprendizagem, bem como a ênfase na diversificação metodológica e técnica, no sentido de suprir as carências dos alunos, pais, professores. Enfim, possibilidades estas, que supram a compreensão da natureza do fenômeno educativo proposto para o Sistema Nacional de Educação que está se buscando ao longo destas discussões com relação à educação brasileira.

Com este estudo, esperou-se trazer uma visão mais próxima da realidade escolar, que ainda traz a cultura tradicional de ensino formal e que ainda não se constitui como ambiente totalmente democrático, que respeita a diversidade e a inclusão com a qualidade almejada nos preceitos do documento base da Conae, mas que traz a perspectiva da busca por estes princípios com novas alternativas que atendam aos interesses da comunidade escolar, buscando compreender que a qualidade da escola dependerá da participação ativa de todos os membros inseridos na mesma, respeitando a individualidade de cada um e buscando nos conhecimentos individuais, novas fontes de enriquecer o trabalho coletivo.

\section{Referências}

BIANCHETTI, Roberto Gerardo. Modelo neoliberal e políticas educacionais. São Paulo: Cortez, 1999.

BRASIL. Construindo o sistema nacional articulado de educação: o plano nacional de educação, suas diretrizes e estratégias de ação, documento referência. Brasília: MEC, 2009.

BRASIL, Constituição da Republica Federativa do Brasil de 1988. Disponível em: $<$ http://www.planalto.gov.br/ccivil 03/constituicao/constitui\%C3\%A7ao.htm>. Acesso em: $1^{\circ}$ jan. 2011.

BRASIL. Política nacional de educação especial. Brasília: MEC/Seesp, 1994.

BRASIL. Política nacional de educação especial na perspectiva da educação inclusiva. Brasília - Brasília: MEC/Seesp, 1998.

BRASIL. Plano decenal de educação. Disponível em: <http://lpp-uerj.net/ olped/documentos/conflitos/area trabalho/1683.pdf>. Acesso em: 14 jun,. 2010.

BRASIL, Lei n. 9394 de 20 de dezembro de 1996. Lei de Diretrizes e Bases da Educação Nacional. Disponível em: <http://www.planalto.gov.br/ccivil 03/Leis/L9394.htm>. Acesso em: 5 jan., 2011.

Definição de multiculturalismo. Disponível em: <http://www.dicio.com.br/multicultura lismo/>. Acesso em 10 jan. 2011.

COOL, César; PALÁCIOS, Jesús; MARCHESI, Álvaro. Desenvolvimento psicológico e educação: necessidades educativas especiais e aprendizagem escolar. Porto Alegre: Artes Médicas, 1995.

EDLER, Rosita Carvalho. Educação inclusiva: com os pingos nos "is". Porto Alegre: mediação, 2004.

FREIRE, Paulo. Pedagogia da autonomia. São Paulo, Paz e Terra, 1997.

FREITAS, Soraia Freitas; RODRIGUES, Davih; KREBS, Rui Jornada (orgs.). Educação inclusiva e necessidades educacionais especiais. Santa Maria: UFSM, 2005. 
FERREIRA, Naura Syria Carapeto; AGUIAR, Márcia. Gestão democrática da educação no contexto da reforma do estado. São Paulo: Cortez, 2001.

GESTÃO ESCOLAR. Revista Nova Escola Gestão Escolar, ano II, n. 11, Ed. Abril. dez. 2010/jan.2011.

LIBÂNEO, José Carlos, OLIVEIRA, João Ferreira; TOSCHI, Mirza Seabra. Educação escolar: políticas, estrutura e organização. São Paulo: Cortez, 2007.

LIBÂNEO, José Carlos. Organização e gestão da escola: teoria e prática. Goiânia: Alternativa, 2001.

LÜCK, Heloisa. Concepções e processos democráticos de gestão educacional. Petrópolis: Vozes, 2008.

LÜCK, Heloisa. Perspectivas de gestão escolar e implicações quanto à formação de seus gestores. In: Em Aberto. Brasília, v. 17, n. 72, 2000, p. 11-33.

LÜDKE, Menga; André, Marli. Pesquisa em educação: abordagens qualitativas. São Paulo: EPU, 1986.

MENEZES, Ebenezer Takuno de; SANTOS, Thais Helena dos. Plano Decenal de Educação para Todos (verbete). Dicionário Interativo da Educação Brasileira EducaBrasil. São Paulo: Midiamix, 2002. Disponível em: <http://www.educabrasil. com.br/eb/dic/dicionario.asp?id=91>. Acesso em: 14 jun., 2009.

MELUCCI, Alberto. Por uma sociologia reflexiva: pesquisa qualitativa e cultura. Petrópolis: Vozes, 2005.

MICHELS, Maria Helena. Gestão, formação docente e inclusão: eixos da reforma educacional brasileira que atribuem contornos à organização escolar. Rev. Bras. Educ. v. 11, n. 33, Rio de Janeiro, 2006, p. 406-423.

MINAYO, Maria Cecilia de Souza. Pesquisa social. Petrópolis: Vozes, 2000.

OLIVEIRA, Maria Marli de. Como fazer pesquisa qualitativa. Petrópolis: Vozes, 2007.

PADILHA, Paulo Roberto. Planejamento dialógico: como construir o projeto políticopedagógico da escola. São Paulo: Cortez, 2001.

PROJETO Político Pedagógico Escola Municipal Clóvis Pestana de Lagoa Vermelha. 2009/2010.

SAVIANI, Dermeval. Escola e democracia: teorias da educação, curvatura da vara, onze teses sobre a educação política. Campinas: Autores Associados, 2005.

SILVA, Edna Lúcia da. Metodologia da pesquisa e elaboração de dissertação. Florianópolis: Laboratório de Ensino a Distância da UFSC, 2001.

TORRES, Rosa Maria. Educação para todos: a tarefa por fazer. Porto Alegre: Artmed, 2001.

UFSM. Estrutura e apresentação de monografias, dissertações e teses: MDT. Santa Maria: UFSM, 2010.

VEIGA, IIma Passos Alencastro (org.). Projeto político-pedagógico da escola: uma construção possível. Campinas: Papirus, 2001. 
Ana Paula da Silva Pozzobon Castanho é professora na Escola Estadual de Ensino Fundamental João Evangelista Saraiva, especialista em Gestão Educacional e educadora especial pela Universidade Federal de Santa Maria.

Endereço: Avenida Presidente Vargas, 1981/04 - 95300-000 - Lagoa Vermelha - RS - Brasil.

E-mail: apozzobon@hotmail.com.

Recebido em 14 de junho de 2013.

Aceito em 25 de julho de 2013. 